INTESTINE

\title{
Acetylated sialic acid residues and blood group antigens localise within the epithelium in microvillous atrophy indicating internal accumulation of the glycocalyx
}

\author{
A D Phillips, A Brown, D M Swallow, S Hicks, S Schüller, S H Murch, J A Walker-Smith
}

Gut 2004;53:1764-1771. doi: 10.1136/gut.2004.041954

See end of article for authors' affiliations

.....................

Correspondence to: Dr A D Phillips,

Centre for Paediatric

Gastroenterology,

Department of Paediatrics

and Child Health, Royal

Free Hospital, Pond St

London NW3 2QG UK;

adphill@rfc.ucl.ac.uk

Revised version received

10 June 2004

Accepted for publication

17 June 2004
Background: Microvillous atrophy, a disorder of intractable diarrhoea in infancy, is characterised by the intestinal epithelial cell abnormalities of abnormal accumulation of periodic acid-Schiff (PAS) positive secretory granules within the apical cytoplasm and the presence of microvillous inclusions. The identity of the PAS positive material is not known, and the aim of this paper was to further investigate its composition. Methods: Formaldehyde fixed sections were stained with alcian blue/PAS to identify the acidic or neutral nature of the material, phenylhydrazine blocking was employed to stain specifically for sialic acid, and saponification determined the presence of sialic acid acetylation. The specificity of sialic acid staining was tested by digestion with mild sulphuric acid. Expression of blood group related antigens was tested immunochemically.

Results: Alcian blue/PAS staining identified a closely apposed layer of acidic material on the otherwise neutral (PAS positive) brush border in controls. In microvillous atrophy, a triple layer was seen with an outer acidic layer, an unstained brush border region, and accumulation within the epithelium of a neutral glycosubstance that contained acetylated sialic acid. Blood group antigens were detected on the brush border, in mucus, and within goblet cells in controls. In microvillous atrophy they were additionally expressed within the apical cytoplasm of epithelial cells mirroring the PAS abnormality. Immuno electron microscopy localised expression to secretory granules.

Conclusions: A neutral, blood group antigen positive, glycosubstance that contains acetylated sialic acid accumulates in the epithelium in microvillous atrophy. Previous studies have demonstrated that the direct and indirect constitutive pathways are intact in this disorder and it is speculated that the abnormal staining pattern reflects accumulation of glycocalyx related material.
M icrovillous atrophy is a definitive diagnosis within the intractable diarrhoea of infancy syndrome. ${ }^{1}$ Onset of diarrhoea is either in the first week of life or after the neonatal period, ${ }^{1}$ and patient survival relies on feeding via parenteral nutrition. The majority of patients die within the first year of life, largely from complications arising from parenteral feeding. ${ }^{1}$ The only potentially "curative" treatment available currently is intestinal transplantation. ${ }^{2-5}$ Microvillous atrophy is termed "microvillous inclusion disease" in the American literature. ${ }^{6}$

The diagnosis is based on the finding of an abnormal accumulation of periodic acid-Schiff (PAS) positive material in the apical cytoplasm, increased cytoplasmic secretory granules, and the presence of intraepithelial microvillous inclusions. ${ }^{167}$ Thiery staining has established that the secretory granules are the ultrastructural representation of the accumulated PAS positive material seen on light microscopy in upper crypt epithelium ${ }^{8}$ so that the two observations actually represent a single abnormality. The underlying pathogenesis in microvillous atrophy is unclear although a cytoskeletal brush border myosin deficiency ${ }^{9}$ has been identified, and it has been shown that the direct and indirect constitutive pathways are intact. ${ }^{10}$ These observations are compatible with the hypothesis that there is a block in exocytosis of an unidentified brush border related material, as exhibited by accumulation of PAS positive secretory granules, due to a deficient molecular myosin-actin based transport system. ${ }^{8}$

Secretory granule accumulation is the first abnormality detected in the epithelial cell life cycle, and the formation of microvillous inclusions appears subsequently in older cells. ${ }^{18}$
Indeed, in both congenital and late onset microvillous atrophy, microvilli appear near normal in regions where secretory granules first accumulate, and microvilli reappear on surface epithelial cells in atypical microvillous atrophy, despite their severe reduction in crypt epithelium. ${ }^{1}$ This indicates that a defect in microvillous biosynthesis is not the basis of the disease and suggests that establishing the identity of the secretory granules should help unravel the basic defect in the disease. The aim of this work was to further investigate the composition of the accumulated PAS positive material within the epithelium using histochemical and immunocytochemical techniques.

\section{PATIENTS AND METHODS}

\section{Patients (table 1)}

Small intestinal tissue was available from two cases of microvillous atrophy (cases 1 and 2 in table 1 ) that had undergone intestinal transplantation and from three cases undergoing proximal small intestinal mucosal biopsy as part of their routine diagnostic investigation. Case 5 had late onset microvillous atrophy (at eight weeks old); the other cases had congenital microvillous atrophy with onset of diarrhoea in the first week of life. Three histologically normal and seven abnormal proximal small intestinal mucosal biopsy samples were used as controls (table 1).

All biopsies were performed with fully informed parental consent as part of the routine investigation of the patients for

Abbreviations: PAS, periodic acid-Schiff; PBS, phosphate buffered saline; FBBG, filamentous brush border glycocalyx; $E M$, electron microscopy 


\begin{tabular}{|c|c|c|c|}
\hline Case No & Sex & $\begin{array}{l}\text { Age at biopsy } \\
\text { (months) }\end{array}$ & Clinical details \\
\hline \multicolumn{4}{|c|}{ Microvillous atrophy } \\
\hline 1 & $\mathrm{~F}$ & 36 & Congenital microvillous atrophy \\
\hline 2 & $\mathrm{~F}$ & 24 & Congenital microvillous atrophy \\
\hline 3 & M & 4 & Congenital microvillous atrophy \\
\hline 4 & $\mathrm{~F}$ & 3 & Congenital microvillous atrophy \\
\hline 5 & $\mathrm{~F}$ & 12 & Late onset microvillous atrophy \\
\hline \multicolumn{4}{|c|}{ Normal histology } \\
\hline 6 & M & 3 & Chronic diarrhoea and FTT \\
\hline 7 & M & 15 & Chronic diarrhoea and FTT \\
\hline 8 & $\mathrm{~F}$ & 24 & $\mathrm{FTT}$ \\
\hline \multicolumn{4}{|c|}{ Abnormal histology } \\
\hline 9 & M & 5 & Coeliac disease \\
\hline 10 & M & 5 & CMSE \\
\hline 11 & $\mathrm{~F}$ & 10 & CMSE \\
\hline 12 & $\mathrm{~F}$ & 12 & $\mathrm{PES} / \mathrm{CMSE}$ \\
\hline 13 & M & 19 & Intractable diarrhoea, epithelial dysplasio \\
\hline 14 & $\mathrm{~F}$ & 20 & Intractable diarrhoea, epithelial dysplasia \\
\hline 15 & $\mathrm{~F}$ & 22 & Coeliac disease \\
\hline
\end{tabular}

gastrointestinal disorders. Histologically normal control samples were from patients with chronic diarrhoea and/or failure to thrive who had no gastrointestinal cause identified for their symptoms.

The cases of coeliac disease (cases 9 and 15) had severe crypt hyperplastic villous atrophy; subsequently, they showed clinical and histological improvement on gluten exclusion and a histological relapse on gluten challenge. ${ }^{11}$

Cases 10 and 11 were diagnosed as cow's milk sensitive enteropathy as they showed a typical mild patchy enteropathy on initial biopsy, rapid clinical improvement following cow's milk exclusion, and a normal histology prior to the uneventful reintroduction of cow's milk back into the diet. ${ }^{12}$ Case 12 developed chronic diarrhoea after an acute diarrhoeal illness, possessed a mild enteropathy on small intestinal mucosal biopsy, and thrived following cow's milk exclusion. ${ }^{13}$

Cases 13 and 14 had intractable diarrhoea with an onset in the first week of life and required management by parenteral nutrition. The mucosa was thin and showed focal piling up of the surface epithelium into tufts, the characteristic appearance of tufting enteropathy, ${ }^{14}$ otherwise termed epithelial dysplasia. ${ }^{15}$ Subsequent biopsies have shown no change in the mucosal appearance. The diagnosis of microvillous atrophy was excluded in these children.

\section{Histochemical methods}

All stains were performed on formalin fixed paraffin wax embedded samples. Sections were cut at $5 \mu \mathrm{m}$, wax was removed using histoclear (Agar Scientific, Stanstead, Essex, UK), and samples were rehydrated into phosphate buffered saline (PBS) through an alcohol series.

\section{Alcian blue/PAS staining ${ }^{16} 17$}

Acid mucopolysaccharides (glycosaminoglycans) are not strongly PAS positive. However, these simple acid and sulphated mucopolysaccharides are well stained by alcian blue.

Sections were stained with $1 \%$ alcian blue 8 GX (Sigma, St Louis, Missouri, USA) in 3\% aqueous acetic acid at pH 2.2 for 60 minutes and washed in running tap water for 10 minutes before immersion in $1 \%$ aqueous periodic acid for five minutes. They were then washed in distilled $\mathrm{H}_{2} \mathrm{O}$ for 10 minutes before staining with Schiff's reagent for 15 minutes, washed in running tap water for 10 minutes, and stained with (Gill solution No 3) haematoxylin prior to observation under the light microscope. In this method neutral glycosubstances stain magenta whereas acidic substances stain blue. Mixtures stain purple.

\section{Sialic acid specific staining ${ }^{17} 18$}

Blocking the staining of neutral sugars with phenylhydrazine following periodic acid oxidation allows sialic acid to be visualised by PAS staining although acetylated sialic acids will not stain.

Sections were stained with $1 \%$ alcian blue $8 \mathrm{GX}$ ( Sigma) in $3 \%$ aqueous acetic acid at $\mathrm{pH} 2.2$ for 30 minutes, rinsed briefly in 3\% acetic acid, and blotted dry. They were then treated with $1 \%$ aqueous periodic acid for two hours at room temperature and washed in running tap water for 10 minutes before immersion in $0.5 \%(\mathrm{w} / \mathrm{v})$ phenylhydrazine hydrochloride for two hours. Overnight incubation in distilled water at room temperature was maintained for 16-24 hours. Schiff staining was then performed for four hours, followed by washing in running water for 10 minutes. Sialic acid stains magenta, O-sulphate esters stain blue, and neutral sugars do not stain.

\section{Saponification to show acetylation of sialic acid ${ }^{18}$} Saponification (treatment with potassium hydroxide) converts acetylated groups to hydroxyl groups that can then be stained by PAS. Phenylhydrazine blocking of neutral sugars allows demonstration of the presence of acetylated sialic acid.

The method is as above for sialic acid specific staining but sections were treated with $0.5 \%(\mathrm{w} / \mathrm{v})$ potassium hydroxide in $70 \%$ ethanol for 15 minutes at room temperature before staining with alcian blue stain. Other steps were the same.

\section{Position of acetylation ${ }^{19}$}

Acetylation at the $\mathrm{C}_{7}$ and/or $\mathrm{C}_{8}$ position was investigated. Periodic acid oxidation converts C9 acetylated sialic acids to C7 aldehydes, C7 acetylated sialic acids to C8 aldehydes, and tissue diols to dialdehydes, but has no effect on C8 acetylated sialic acids. Sodium borohydride reduction converts aldehydes into primary alcohols, which are Schiff negative. Saponification removes o-acetyl substituents from the C8 class and the modified C7 class, making them PAS positive.

Sections were immersed in $1 \%$ aqueous periodic acid for 30 minutes, washed in distilled water for 10 minutes, and treated with $0.1 \%$ sodium borohydride in $1 \% \mathrm{Na}_{2} \mathrm{HPO}_{4}$ for 30 minutes. After washing in water, sections were saponified for 15 minutes, washed in water, and exposed again to $1 \%$ periodic acid for five minutes. Sections were then washed in running water for 10 minutes before staining with Schiff 
reagent for four hours. Sialic acid with side chain substituents at $\mathrm{C}_{7}$ and/or $\mathrm{C}_{8}$ stains red. Specificity controls, omitting the saponification step, should be unstained.

\section{Sialic acid digestion to show specificity of staining 2021}

Sections were saponified for 15 minutes at room temperature and washed in water for 10 minutes, prior to exposure to $0.05 \mathrm{M} \mathrm{H}_{2} \mathrm{SO}_{4}$ for one hour at $80^{\circ} \mathrm{C}$. Sections were then washed in water for 10 minutes before specific staining for sialic acid, as described in the sialic acid specific staining method above. O-sulphate esters stain blue, neutral sugars do not stain. Sialic acid staining should be markedly reduced in comparison with that identified previously and to control sections incubated with PBS rather than sulphuric acid.

\section{Immunohistochemical methods}

The following blood group related antibodies were used: (a) a commercially available $\mathrm{H}$ blood group antibody which recognises $\mathrm{O}$ and $\mathrm{H}$ blood group antigens (Lorne Laboratories, UK); (b) a commercially available $\mathrm{Le}^{\mathrm{a}}$ antibody (Lorne Laboratories, UK). Both of these antibodies were kindly provided by the Royal Free Hospital NHS Trust Haematology Department; (c) a mouse monoclonal antibody, termed mbbm-4 (or IG7FI), against Lewis Le $^{\mathrm{a}}$ related structures $^{22}$; (d) a mouse monoclonal antibody, termed mbbm-1 (or VA4), raised against high molecular weight human jejunal glycoproteins, that recognises blood group A antigen. ${ }^{23}$ The titres of the antibodies were 1:20, 1:20, 1:10, and 1:10, respectively.

Paraffin wax embedded formalin fixed samples were treated as described in the histochemistry section to bring them to PBS. Sections were pretreated with $1.5 \%$ bovine serum albumin in PBS to block non-specific primary antibody staining, prior to staining with the primary antibodies listed
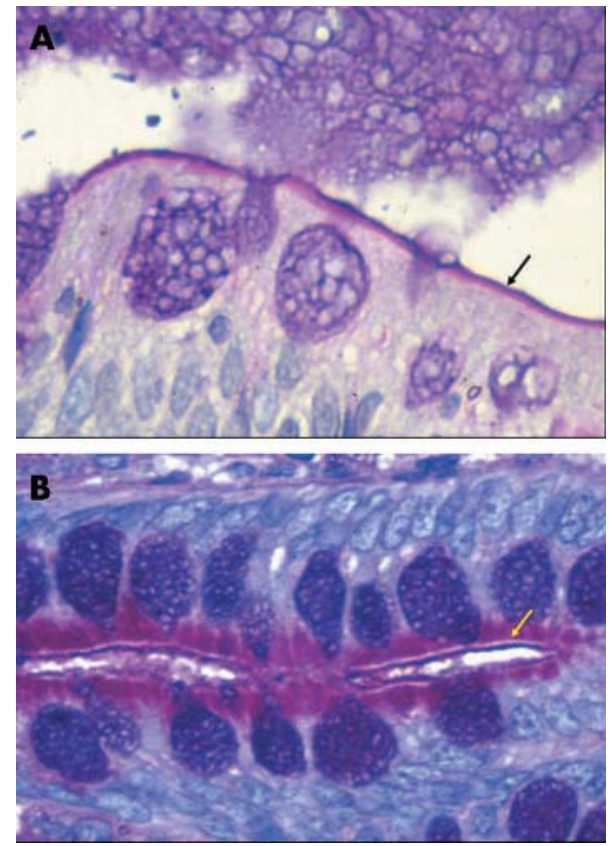

Figure 1 Alcian blue/periodic acid-Schiff staining. (A) Control (case 7). Magenta stained brush border, indicating the presence of neutral glycosubstances, with a tightly apposed purple stained luminal acidic layer, presumably attached mucus (arrow). Note purple goblet cells and mucus in lumen. (B) Microvillous atrophy (case 1). Magenta stained neutral glycosubstance accumulated within the apical cytoplasm. No magenta brush border stain but the tightly apposed luminal purple staining acidic layer remained, producing a triple layered sandwich effect (arrow). above, for one hour at $37^{\circ} \mathrm{C}$. Indirect immunofluorescent staining was performed using FITC conjugated goat antimouse secondary antibodies (1:100 dilution for one hour at $\left.37^{\circ} \mathrm{C}\right)$, sections were washed in PBS mounted in citifluor (Agar Scientific Ltd), and viewed under a Zeiss fluorescence microscope.

\section{Immune electron microscopy}

Immuno electron microscopy (EM) was performed on case 2 (table 1) using the IG7FI anti-Le ${ }^{\mathrm{a}}$ antibody to determine if the positive staining seen at the light microscope level was localised to the secretory granules. A histologically normal control (case 6 in table 1 ) was also stained. The only material available was glutaraldehyde/osmium fixed and TAAB resin embedded. Thin sections (100 nm) were cut and mounted onto 200 mesh Nickel grids. Grids were floated on nonimmune swine serum (1:10 dilution, 20 minutes at room temperature) in PBS to block non-specific staining, washed in PBS, stained with IG7FI anti-Le ${ }^{\mathrm{a}}$ antibody ( $1: 10$ dilution for two hours at room temperature), washed in PBS, stained with goat antimouse immunoglobulin $10 \mathrm{~nm}$ gold conjugated secondary antibody (1:20 dilution for two hours at room temperature), and washed in distilled water. Prior to observation in a JEOL 1200 ExII transmission EM at $80 \mathrm{kV}$ accelerating voltage, sections were double stained in uranyl acetate $\left(10\right.$ minutes at $37^{\circ} \mathrm{C}$ ) and lead citrate (three minutes at room temperature), washed in distilled water, and allowed to dry.

\section{RESULTS}

\section{Histochemistry}

Alcian blue/PAS staining in histologically normal and abnormal controls showed that mucins within goblet cells largely stained purple, indicating a mixture of acidic and neutral substances. There was however a gradient of staining from the crypt base to the villus with some goblet cells staining magenta near the crypt base, especially in the duodenum. There were more goblet cells in the ileum compared with the duodenum. Mucus in the crypt lumen and in between villi stained a deep purple. The brush border stained magenta, indicating the presence of neutral glycosubstances, with a tightly apposed luminal acidic layer, presumably attached mucus, which stained deep purple (fig 1A).

In all microvillous atrophy cases the abnormally accumulated material within the apical cytoplasm stained magenta, demonstrating it was a neutral glycosubstance. The neutral magenta positive staining of the brush border seen in controls was absent. However, the tightly apposed luminal purple staining acidic layer remained, producing a triple layered sandwich effect (fig 1B). This was readily identified in the upper crypt region in cases $1-4$, and was not clearly present on the exposed surface epithelium. Goblet cells appeared as in controls. Case 5 (late onset microvillous atrophy) showed areas where the triple layer effect was present as well as areas where the brush border stained as in controls (that is, magenta with a tightly apposed purple luminal acidic layer).

Specific staining for sialic acid showed positive goblet cells and mucus and a faintly positive brush border in controls (fig 2A). In microvillous atrophy there was faintly positive staining in the epithelium, and goblet cells were positive as in controls (fig 2C).

Saponification (to make acetyl groups PAS positive) prior to alcian blue/PAS staining with phenylhydrazine blocking (to stop neutral sugar staining) demonstrated the presence of acetylated sialic acids in goblet cells and the brush border in controls (fig 2B). In microvillous atrophy, positive staining for acetylated sialic acid was identified in goblet cells and in 

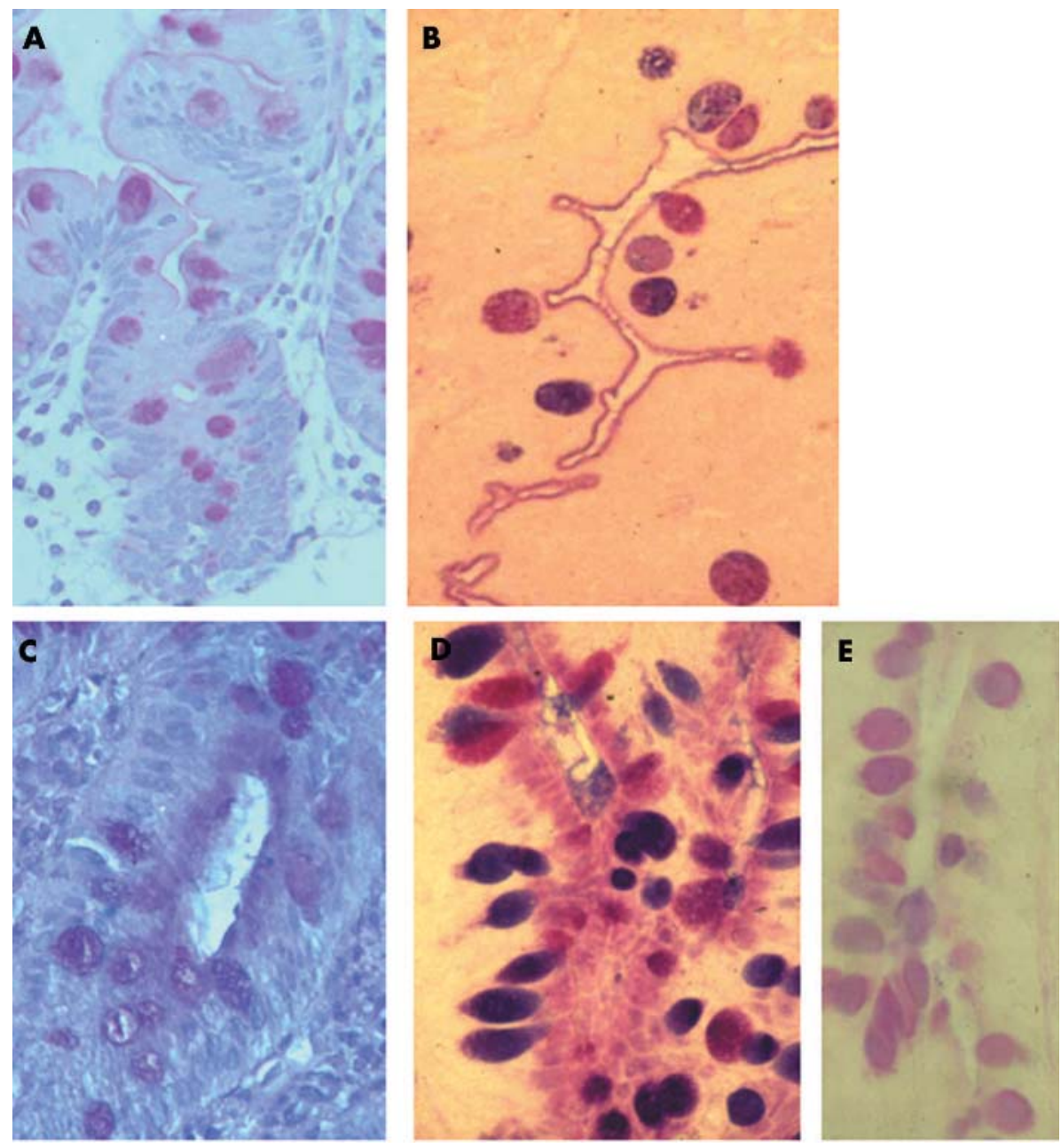

Figure 2 Staining for sialic acid. Control (A) case 7 showed faint brush border and goblet cell stain for sialic acid. (B) Stain for acetylated sialic acid showing the same pattern as in (A) but more strongly stained. Microvillous atrophy (case 2). (C) Stain for sialic acid showing similar distribution to alcian blue/periodic acid-Schiff stain. (D) Positive staining for acetylated sialic acid in apical cyłoplasm and goblet cells. (E) Reduced staining following sulphuric acid digestion confirming the presence of acetylated sialic acid.

crypt epithelium where superficial brush border and apical epithelial cytoplasmic staining was seen (fig 2D). The body of the brush border did not stain, again producing a triple layered sandwich effect. Removal of acetylated sialic acids using saponification and sulphuric acid digestion showed a
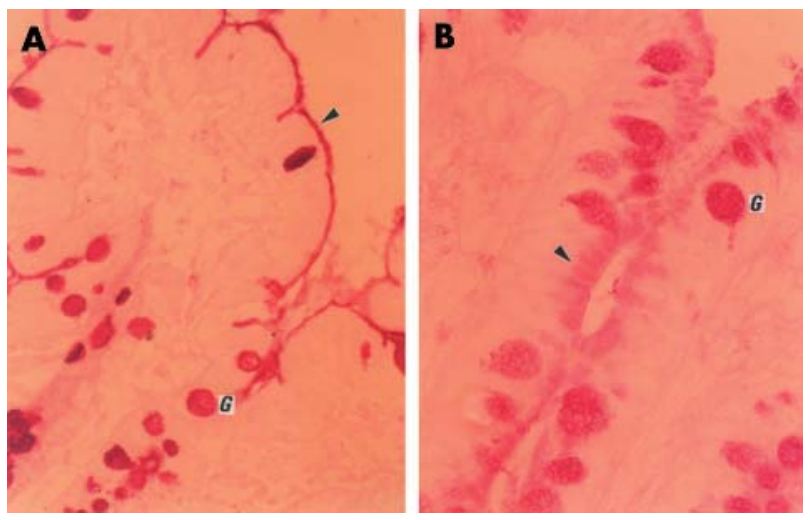

Figure 3 Staining for sialic acid $C_{7} / C_{8}$ position of acetylation.

(A) Control (case 7) showing brush border (arrowhead) and goblet cell (G) staining. (B) Microvillous atrophy (case 2) staining in upper crypt apical cytoplasm (arrowhead) and goblet cells (G). marked reduction in positive staining, confirming the presence of acetylated sialic acids (fig 2E). Positive red staining indicating acetylation at the $\mathrm{C}_{7}$ and $\mathrm{C}_{8}$ positions was seen in areas which had demonstrated the presence of acetylated sialic acids in controls and microvillous atrophy (fig 3A, 3B). Staining was markedly reduced with omission of the saponification step (data not shown).

\section{Immunostaining}

Consistent staining in the patient groups was not expected as blood groups would vary between individuals.

No case showed staining with the blood group $\mathrm{H}$ antibody.

\section{Lewis blood group}

$\mathrm{Le}^{\mathrm{a}}$ and Lewis $\mathrm{Le}^{\mathrm{a}}$ related antibody staining gave similar results. Goblet cells and mucus were positive in histologically normal and abnormal cases, apart from case 12 where luminal mucus was positive but goblet cells did not stain. The brush border was positive in all cases (fig 4A) apart from case 12. Cases 7, 8, 9, and 14 showed patchy brush border staining, and cases 11 and 13 showed superficial and patchy staining implying that mucus attached to the brush border might be staining, rather than the brush border. Staining was reduced in the crypt region.

Microvillous atrophy cases 2 and 3, but not the other cases, showed positive staining within the apical cytoplasm of 

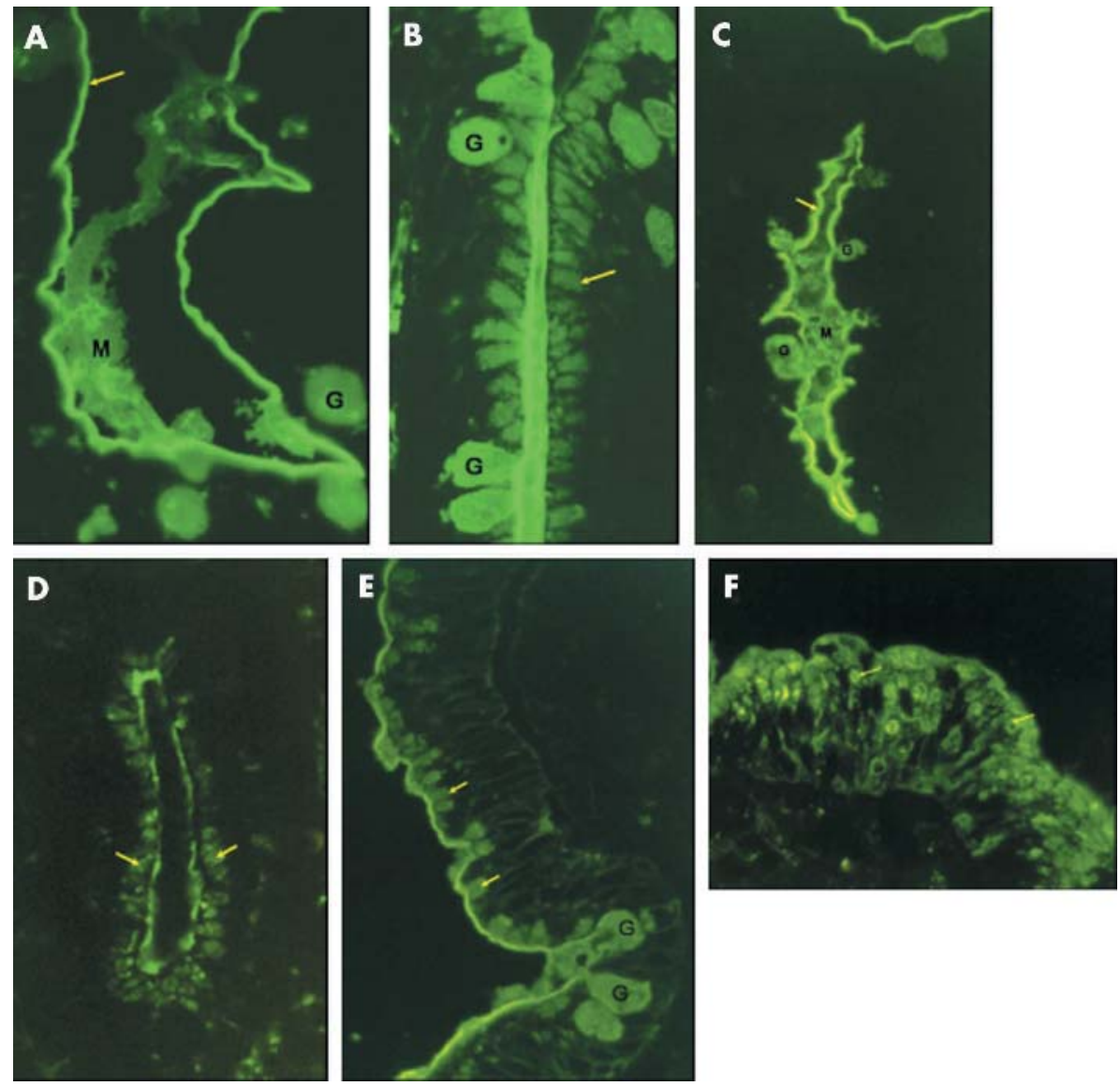

Figure 4 Blood group staining. Lewis Le $e^{a}$ related antibody staining. Controls: (A) case 10 with positive fluorescence in brush border (arrow), goblet cells (G), and luminal mucus (M). Microvillous atrophy: (B) case 2 demonstrating positive staining within the apical cytoplasm (arrow) of upper crypt cells in a similar location to the abnormal accumulation of periodic acid-Schiff positive material, and goblet cells (G). Blood group A staining: controls: (C) case 14 showing brush border (arrow), goblet cell (G), and mucus (M) staining. Microvillous atrophy: (D) positive staining within the upper crypt epithelium (arrow) (case 2), (E) apical cytoplasm of low villous epithelium (arrow) (case 5), and (F) circular staining within surface epithelium (arrow) (case 3).

upper crypt cells in a similar location to the abnormal accumulation of PAS positive material (fig 4B). Otherwise, all microvillous atrophy cases showed positive brush border, goblet cell, and luminal mucus staining, as in controls. Cases 2, 3, and 4, but not cases 1 and 2, showed some positive intracellular staining in surface exposed epithelial cells that may reflect microvillous inclusion bodies and/or vesicular bodies (fig 4C). ${ }^{6}$

\section{Blood group A \\ Controls}

Cases 6, 10 and 11 did not stain with the VA4 antibody. Histologically normal cases 7 and 8 showed very small areas of positive staining in luminal mucus. Histologically abnormal cases 9, 12, 13, and 14 showed brush border, goblet cell, and mucus staining (fig 4D).

\section{Microvillous atrophy}

Cases 1 and 5 showed positive staining within the apical cytoplasm of upper crypt (case 1) (fig 4E) and low villous (case 5) (fig 4F) epithelium in a similar location to the abnormal accumulation of PAS positive material. These two cases also showed some circular cytoplasmic staining in the surface exposed epithelium, perhaps reflecting the presence of microvillous inclusions or vesicular bodies. ${ }^{6}$ Cases 2 and 5 demonstrated positive goblet cell and mucus staining; other cases did not stain.

\section{Immuno EM}

Immuno EM was performed on histologically normal control case 6 (table 1) and on microvillous atrophy case 2 (table 1) using the IG7FI anti $\mathrm{Le}^{\mathrm{a}}$ antibody to determine if the positive staining seen at the light microscope level was localised to the secretory granules. The control had gold particles identified on mucus within goblet cells (fig 5A) and in the brush border, where labelling was seen on the surface, between and on microvilli (fig 5B). In microvillous atrophy, gold labelling was identified on secretory granules (figs 5C, 5D) and on mucus within goblet cells, as seen in controls. A low level of gold labelling was seen within microvillous inclusions (data not shown). No nuclear, Golgi complex, mitochondrial, or rough endoplasmic reticulum gold labelling was found, and no staining was identified in Paneth cells.

\section{DISCUSSION}

The aim of this study was to investigate the nature of the secretory granules that accumulate within the intestinal epithelium in cases of microvillous atrophy ${ }^{16-8}$ and produce an abnormal PAS positive staining reaction. ${ }^{8}$ Histochemical and immunostaining approaches were employed.

Alcian blue/PAS staining showed that the brush border region in both histologically normal and abnormal controls contained neutral glycosubstances with a tightly apposed outer acidic layer, presumably mucus. Thus mucus, as well as appearing in the crypt lumen and above the mucosal surface to produce the unstirred layer, appears to bind directly to the 

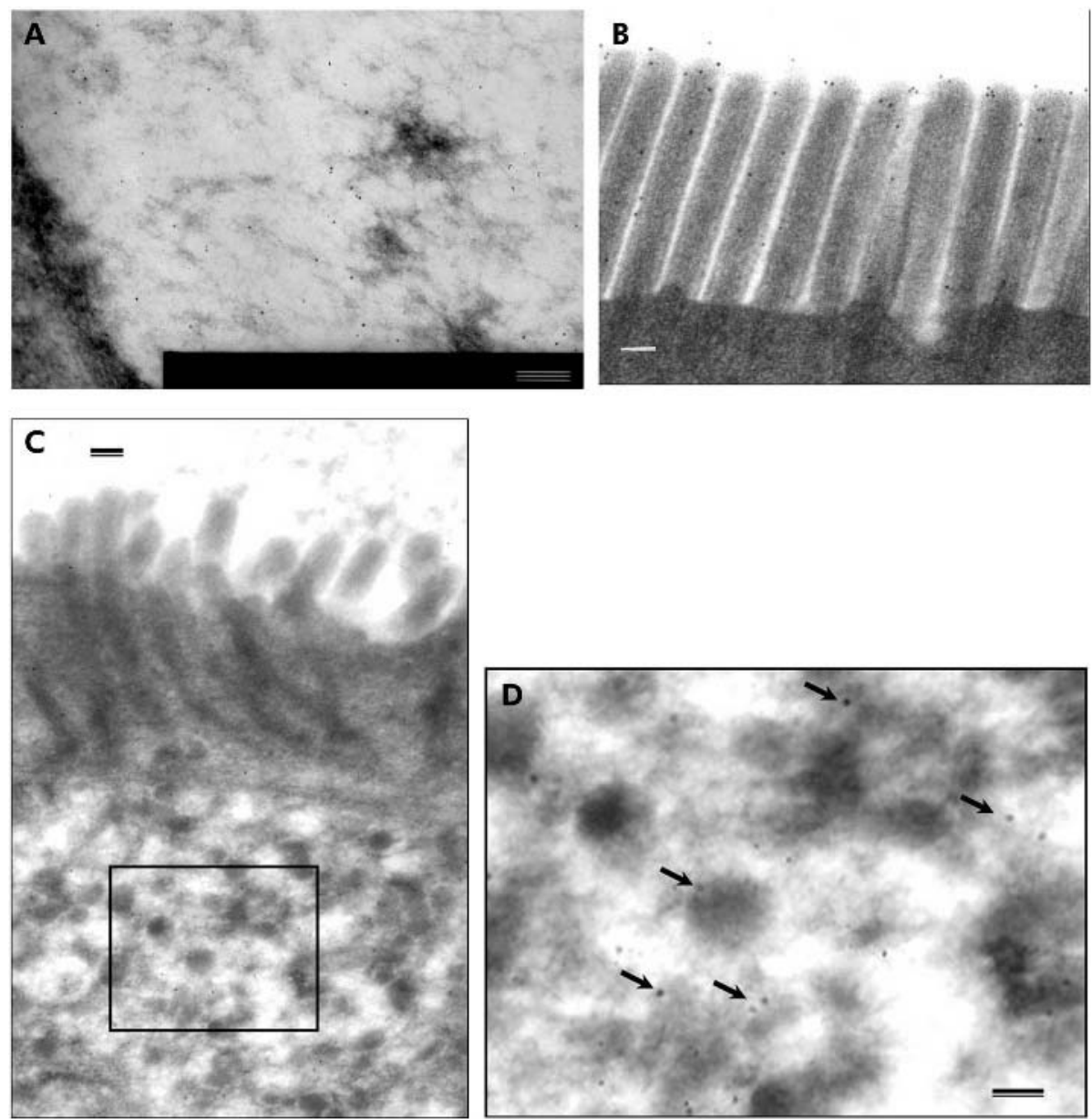

Figure 5 Immuno electron microscopy. Control (case 6): gold particles on (A) mucus within goblet cell and (B) microvilli. Microvillous atrophy (case 2): (C) view of microvilli and secretory granules. Rectangle marks inset (D) showing gold labelling present on secretory granules (arrows). Bar $=100 \mathrm{~nm}$.

brush border, adding a discrete layer to the glycocalyx that must be negotiated by both nutrients and pathogens alike. This is not a well described phenomenon, although galectin-1, a mammalian galactoside binding lectin, has been shown to cross link mucus and glycocalyx components in the rat, ${ }^{24}$ suggesting a specific mechanism for the association.

The PAS positive stain of the brush border in controls was absent in microvillous atrophy indicating that a neutral brush border glycosubstance is missing. The accumulated material within the epithelium in microvillous atrophy stained positively with PAS demonstrating that it is a neutral glycosylated substance of similar staining characteristics to the missing brush border material, suggesting that there is a block in its exocytosis. The tightly apposed outer acidic layer identified in controls was also seen in microvillous atrophy in crypt regions, producing a triple layered staining effect. This alcian blue positive layer was not seen on surface exposed epithelium where ultrastructural studies showed short or absent microvilli, whereas microvilli appeared near normal in crypt regions. ${ }^{167}$ Thus mucus still adheres to the brush border region in microvillous atrophy where intact microvilli are still present but there is a defect in the glycobiological makeup of the brush border. This presence of a tightly bound layer of mucus on the brush border in microvillous atrophy explains the profile seen by scanning photometry where a PAS positive brush border peak was seen as well as accumulation of PAS positive material within the cell. ${ }^{8}$ In this earlier paper, the possibility of either a partial block in exocytosis or the presence of exogenous PAS positive material was put forward to explain the findings. ${ }^{8}$ Alcian blue/PAS staining has now shown that the most likely explanation is exogenous mucus adhering to the microvilli, and leads to the deduction that there is a complete block in exocytosis of the PAS positive material, which would normally reside in the brush border.

Brush border related enzymes (for example, disaccharidases, peptidases) are glycosylated and the above result could be interpreted to indicate that these enzymes are accumulating within the cell. However, we have shown normal synthesis and insertion of these enzymes into the apical membrane (that is, intact direct and indirect constitutive pathways) in microvillous atrophy, and we could not detect their accumulation within secretory granules. ${ }^{10}$ Thus some other epithelial component(s) must be responsible.

The histochemical investigation identified acetylated sialic acid accumulation within the epithelium in microvillous atrophy in a distribution that matched the abnormal PAS staining pattern, whereas it was brush border located in controls. Acetylated sialic acid has been identified as a common component of the glycocalyx in animals, ${ }^{25}$ raising the possibility that microvillous atrophy involves a defect in exocytosis of the glycocalyx or some of its components. The immuno EM results would support this contention as positive Le $^{\mathrm{a}}$-like antibody staining in the control localised to the glycocalyx, and this immunoreactivity was found in secretory granules in microvillous atrophy. Thus we have morphological and histochemical evidence of a defect in glycocalyx component localisation. 
The glycocalyx, the "sugar-rich" covering that coats plasma membranes, may be an extraneous coat and/or an integral part of the plasma membrane. ${ }^{26}$ It is considered to form a hydrophilic polyanionic gel coat on the enterocyte surface and is thought to maintain cell surface charge, protect against physical trauma, regulate ionic and macromolecular access, and form a cationic store. ${ }^{27}$ Thus absence of the glycocalyx would have profound consequences on normal cell function and may result in an inability to maintain cellular homeostasis. This could explain why the vast majority of cases of microvillus atrophy do not exhibit hydramnios, ${ }^{1}$ as the amniotic fluid, which is swallowed by the fetus and bathes the luminal surface of the gut, is comparable in osmolality to serum, ${ }^{28}{ }^{29}$ resulting in no osmotic pressure across the gut in utero. This changes dramatically following birth and could explain the rapid onset of symptoms.

In the intestine, there are many glycosylated proteins associated with the apical epithelial membrane and it is uncertain which ones provide the physical characteristics of the glycocalyx listed above, or whether a particular component is responsible. Components include brush border enzymes, mucins, and a filamentous matrix (termed the filamentous brush border glycocalyx (FBBG)), the major component of which is an approximately $400 \mathrm{kDa}$ molecular weight transmembrane mucin-type glycoprotein ${ }^{30}$ containing O-acetylated sialic acid. ${ }^{25}$ The $400 \mathrm{kDa}$ FBBG in the rabbit has the same morphological appearance as the fine filamentous material on the microvilli of humans and various other species, including bats, rodents, and amphibians. ${ }^{31}$ As stated above, brush border enzymes are normally inserted into the apical membrane in microvillous atrophy, ${ }^{10}$ and we could not detect differences in alcian blue staining of goblet cells and mucus between controls and microvillous atrophy cases. Thus the FBBG could be responsible for the abnormal histochemical staining pattern.

In humans, the membrane associated mucins which are produced by intestinal epithelia and include MUC1, MUC3, MUC4, MUC13,32 and MUC17 $7^{33}$ may form part of the glycocalyx and one or other of these may be the human orthologue of the FBBG. It is feasible that these glycoproteins are part of the accumulated PAS positive material. However, antibodies against these substances which work on formalin fixed paraffin wax embedded sections are not available in all cases, or deglycosylation, ${ }^{34}$ antigen retrieval, and reduction/ alkylation ${ }^{35}$ techniques may be required, leading to capricious staining results (unpublished observation). As fresh biopsy material becomes available we will be able to pursue this possibility using frozen sections, where antigen preservation should be improved.

We also studied localisation of certain blood group antigens in this work and detected their presence in a similar distribution to the PAS staining abnormality in microvillous atrophy, but on an individual basis, as would be expected with blood group determinants. A, B, H, and Lewis antigens are expressed on glycoproteins in the brush border of the human intestine. This has been shown for disaccharidases, peptidases, and alkaline phosphatases. ${ }^{23}$ However, it has also been shown for blood group A determinants in the rabbit where it was strongly localised to the FBBG and to brush border hydrolases. ${ }^{36}{ }^{37}$ These findings are compatible with the hypothesis that the glycocalyx, or its components, accumulate within the epithelial cell in microvillous atrophy, and this is seen morphologically as an accumulation of PAS positive secretory granules. The relationship between this abnormality and the finding of microvillous inclusions in epithelial cells at a later stage of their development ${ }^{18}$ is unclear. However, it is possible that accumulation of this glycocalyx related material might interrupt the normal process of the maintenance of the brush border, which turns over at a high rate, $^{38}$ and stimulate the self assembly of microvilli within the cell resulting in the formation of microvillous inclusions. Alternative hypotheses that have been recently suggested include a genetic defect affecting apical membrane traffic ${ }^{39}$ and autophagocytosis of the apical membrane. ${ }^{40}$ In the former paper there is agreement that vesicular traffic may be interrupted but disagreement in what this traffic represents. We have previously reported normal localisation of brush border membrane hydrolases and peptidases in several cases of the disease, ${ }^{10}$ whereas Ameen and Salas ${ }^{39}$ report diffuse subapical and apical membrane immunolocalisation of sucrase-isomaltase in a single case report. In contrast, in agreement with our findings, others have reported dense sucrase-isomaltase brush border labelling in most enterocytes. ${ }^{40}$

In summary, we have presented morphological, histochemical, and immunostaining evidence of an abnormality in the exocytosis of the glycocalyx in microvillous atrophy. Whether the consequences of this abnormality are sufficient to explain the severe clinical picture in microvillous atrophy awaits further investigation.

\section{ACKNOWLEDGEMENTS}

We are very grateful to Dr Deirdre Kelly, Dr Sue Beath, Professor Faro Raafat, Alan Brownhill, and the transplantation team of Birmingham Children's Hospital for their help in providing the surgical samples of the cases of microvillous atrophy. We also wish to thank our colleagues in the Haematology Department, Royal Free Hospital, for providing blood group $\mathrm{H}$ antibodies, and Dr S Maroux (Faculté des Sciences et Techniques de St Jérôme, Université d'Aix-Marseillee III, France) and Dr Jacques Bara (U-482 INSERM, Hôpital St-Antoine, Paris, France) for helpful advice.

\section{Authors' affiliations}

A D Phillips, A Brown, S Hicks, S Schüller, S H Murch, J A Walker-

Smith, Centre for Paediatric Gastroenterology, Royal Free Hospital, London, UK

D M Swallow, Galton Laboratory, Department of Biology, UCL, Wolfson House, London, UK

\section{REFERENCES}

1 Phillips AD, Schmitz J. Familial microvillous atrophy: a clinicopathological survey of 23 cases. J Pediatr Gastroenterol Nutr 1992;14:380-96.

2 Schofield DE, Agostini RM, Yunis M. Gastrointestinal microvillus inclusion disease. Am J Clin Pathol 1992;98:119-24.

3 Herzog D, Atkinson P, Grant D, et al. Combined bowel-liver transplantation in an infant with microvillus inclusion disease. J Pediatr Gastroenterol Nutr 1996;22:405-8.

4 Oliva M, Perman JA, Saavedra JM, et al. Successful intestinal transplantation for microvillus inclusion disease. Gastroenterol 1994;106:771-4.

5 Randak C, Langnas AN, Kaufman SS, et al. Pretransplant management and small bowel-liver transplantation in an infant with microvillus inclusion disease. J Pediatr Gastroenterol Nutr 1998;27:333-7.

6 Cutz E, Rhoads JM, Drumm B, et al. Microvillus inclusion disease: an inherited defect of brush-border assembly and differentiation. N Eng J Med 1989;320:646-51

7 Phillips $A D$, Jenkins $P$, Raafat $F$, et al. Congenital microvillous atrophy: specific diagnostic features. Arch Dis Child 1985:60:135-40.

8 Phillips AD, Szafranski M, Man LY, et al. Periodic acid-Schiff staining abnormality in microvillous atrophy: photometric and ultrastructural studies. J Pediatr Gastroenterol Nutr 2000;30:34-42.

9 Carruthers L, Phillips AD, Dourmashkin R, et al. Biochemical abnormality in brush border membrane protein of a patient with congenital microvillous atrophy. J Pediatr Gastroenterol Nutr 1985;4:902-7.

10 Phillips AD, Fransen JAM, Hauri HP, et al. The constitutive exocytotic pathway in microvillous atrophy. J Pediatr Gastroenterol Nutr 1993; 17:239-46.

11 Meuwisse GW. Diagnostic criteria in coeliac disease. Acta Paediatr Scand 1970:59:461-3.

12 Walker-Smith JA, Digeon B, Phillips AD. Evaluation of a casein and a whey hydrolysate for treatment of cow's- milk-sensitive enteropathy. Eur J Pediatr 1989; 149:68-71

13 Walker-Smith JA. Cow's milk intolerance as a cause of post-enteritis diarrhea. J Pediatr Gastroenterol Nutr 1982;1:163-73.

14 Reifen RM, Cutz E, Griffith AM, et al. Tufting enteropathy a newly recognized clinicopathological entity associated with refractory diarrhea in infants. J Pediatr Gastroenterol Nutr 1994;18:379-85. 
15 Patey N, Scoazec JY, Cuenod-Jabri B et al. Distribution of cell adhesion molecules in infants with intestinal epithelial dysplasia (tufting enteropathy). Gastroenterology 1997; 113:833-43.

16 Bancroft GJ, Stevens A. Theory and practice of histological techniques. Edinburgh, UK: Churchill Livingstone, 1982.

17 Culling CFA, Reid PE. Histochemistry of sialic acids (review). Cell Biol Monogr 1982;10:173-93.

18 Park CM, Reid PE, Owen DA, et al. Histochemical procedures for the simultaneous visualisation of neutral sugars and either sialic acid and its side chain O-acyl variants or O-sulphate ester. II. Methods based upon the periodic acid-phenylhydrazine-Schiff reaction. Histochem J 1987: 19:257-63.

19 Reid PE, Culling CF, Dunn WL, et al. Differences between the O-acetylated sialic acids of the epithelial mucins of human colonic tumors and normal controls: a correlative chemical and histochemical study. J Histochem Cytochem 1980;28:217-22

20 Culling CF, Reid PE, Dunn WL. A problem in the removal of sialic acid by acid hydrolysis. Stain Technol 1974;49:317-8.

21 Culling CF, Reid PE, Clay MG, et al. The histochemical demonstration of Oacylated sialic acid in gastrointestinal mucins. Their association with the potassium hydroxide-periodic acid-Schiff effect. J Histochem Cytochem 1974;22:826-31.

22 Dickson L, Richman PI, Shaw MA, et al. Three antibodies to human intestinal brush border membrane are characterized as anti-Le(a). J Immunogenet 1989:16:193-202.

23 Green FR, Greenwell P, Dickson L, et al. Expression of the ABH, Lewis, and related antigens on the glycoproteins of the human jejunal brush border. Sub Cell Biochem 1988;12:119-53.

24 Wasano K, Hirakawa Y. Recombinant galectin-1 recognizes mucin and epithelial cell surface glycocalyces of gastrointestinal tract. J Histochem Cytochem 1997; 45:275-83.

25 Maury J, Bernadac A, Rigal A, et al. Expression and glycosylation of the filamentous brush border glycocalyx (FBBG) during rabbit enterocyte differentiation along the crypt-villus axis. J Cell Sci 1995; 108:2705-13

26 Ito S. Structure and function of the glycocalyx. Fedn Proc 1969;28:12-25.
27 Gupta BL. The relationship of mucoid substances and ion and water transport, with new data on intestinal goblet cells and a model for gastric secretion. Symp Soc Exp Biol 1989;43:81-1 10.

28 Gillibrand PN. Changes in the electrolytes, urea and osmolality of the amniotic fluid with advancing pregnancy. J Obstet Gynaec Brit Cwlth 1969:76:898-905

29 Sinha RS, Carlton M. The volume and composition of amniotic fluid in early pregnancy. J Obstet Gynaec Brit Cwlth 1970;77:211-14.

30 Maury J, Nicoletti C, Guzzo-Chambraud L, et al. The filamentous brush border glycocalyx, a mucin-like marker of enterocyte hyper-polarisation. Eur J Biochem 1995;228:323-31.

31 Ito $\mathrm{S}$. The enteric surface coat on cat intestinal microvilli. J Cell Biol 1965;27:475-91.

32 Williams SJ, Wreschner DH, Tran M, et al. Muc13, a novel human cell surface mucin expressed by epithelial and hemopoietic cells. J Biol Chem $2001 ; 276: 18327-36$

33 Gum JR Jr, Crawley SC, Hicks JW, et al. MUC17, a novel membrane-tethered mucin. Biochem Biophys Res Commun 2002;291:466-75.

34 Bara J, Imberty A, Perez S, et al. A fucose residue can mask the MUC-1 epitopes in normal and cancerous gastric mucosae. Int J Cancer 1993;54:607-13

35 Park HU, Kim JW, Kim GE, et al. Aberrant expression of MUC3 and MUC4 membrane-associated mucins and sialyl Lex antigen in pancreatic intraepithelial neoplasia. Pancreas 2003;26:E48-54.

36 Gorvel JP, Wisner-Provost A, Maroux S. Identification of glycoproteins bearing human blood group $A$ determinants in rabbit enterocyte plasma membranes. FEBS Lett 1982;143:17-20.

37 Bernadac A, Gorvel JP, Feracci H, et al. Human blood group A-like determinants as markers of intracellular pools of glycoproteins in secretory and absorbing cells of A+ rabbit jejunum. Biol Cell 1984;50:31-6.

38 Stidwell RP, Wysolmerski T, Burgess DR. The brush border cytoskeleton is not static: in vivo turnover of proteins. J Cell Biol 1984;98:641-5.

39 Ameen NA, Salas PJ. Microvillus inclusion disease: a genetic defect affecting apical membrane protein traffic in intestinal epithelium. Traffic 2000;1:76-83

40 Reinshagen K, Naim HY, Zimmer KP. Autophagocytosis of the apical membrane in microvillus inclusion disease. Gut 2002:51:514-21.

\section{EDITOR'S QUIZ: GI SNAPSHOT}

\section{Unexplained digestive bleeding in a cirrhotic patient}

\section{Clinical presentation}

A 50 year old White man with cirrhosis due to hepatitis C virus (HCV) infection was admitted to our hospital for severe anaemia and intermittent melena. At admission, haemoglobin was $6 \mathrm{~g} / \mathrm{dl}$. Upper endoscopy disclosed grade 1 oesophageal varices, no gastric varices, and severe portal hypertensive gastropathy with a mosaic-like pattern in the fundus and confluent cherry red spots compatible with gastric antral vascular ectasia in the antrum. Transvenous liver biopsy confirmed HCV related cirrhosis, and the hepatic venous pressure gradient was $9 \mathrm{~mm} \mathrm{Hg}$. Despite the transfusion of 3 units of packed red cells, intermittent melena persisted and haemoglobin continued to decrease. Ileocolonoscopy disclosed a normal colon without hypertensive colopathy but terminal ileoscopy revealed particular lesions (fig l).

\section{Question}

What is the nature of these ileal lesions? Are they related to the cirrhosis?

See page 1780 for answer

This case is submitted by:

S Evrard, O Le Moine, J Devière, P Yengue, N Nagy, M Adler, A Van Gossum Department of Hepatogastroenterology, Erasme Hospital, Brussels, Belgium

Correspondence to: Professor A Van Gossum, Department of Hepatogastroenterology, Erasme Hospital, 808, Route de Lennik, 1070 Brussels, Belgium; andre.van.gossum@ulb.ac.be

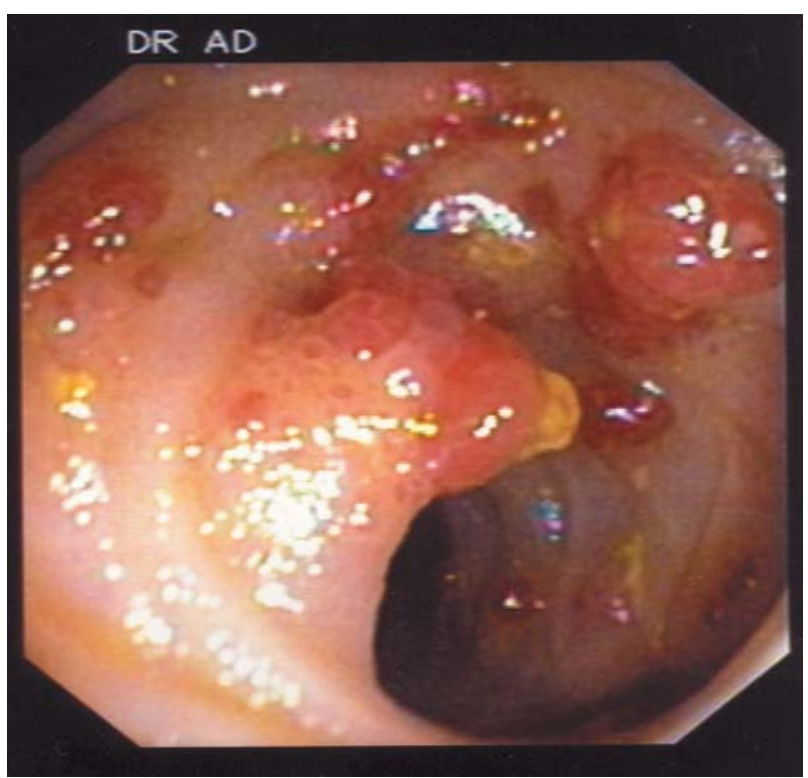

Figure 1 Terminal ileoscopy. 